\title{
A study of menopausal symptoms and its impact on lives of Nepalese perimenopausal and postmenopausal women
}

\section{Shrestha NS', Pandey A $^{2}$}

${ }^{1}$ Nira Singh Shrestha, Associate Professor; ${ }^{2}$ Asmita Pandey, Resident; Department of Obstetrics and Gynecology, Kathmandu Medical College Teaching Hospital, Kathmandu, Nepal

\begin{abstract}
Background: Menopausal health has not been given any consideration till the recent years in developing countries. With the improving status of women in the society, more and more women are seeking help for their menopausal problems. Objectives: The study aimed to find out the prevalence of menopausal symptoms and its impact on life of perimenopausal and postmenopausal women attending gynecology outpatient department at Kathmandu Medical College Teaching Hospital.

Methods: A hospital based cross sectional study was done at Kathmandu medical college teaching hospital among 100 perimenopausal and postmenopausal women attending gynecology outpatient department in the month of August 2016. A pretested questionnaire was administered to the women selected by convenience sampling. Data was analyzed by SPSS version 20 and presented in percentage and frequency table.

Results: The mean age of the women in the study population was 49.98 years(SD \pm 6.18$)$ and mean age at menopause was 48.02 years ( $S D \pm 2.12$ ). Ninety four percent of the women had one or more of the menopausal symptoms. The commonest menopausal symptom was mood swings and irritability ( $80 \%$ and $68 \%$ respectively) followed by vasomotor symptoms like hot flashes in $42 \%$ and night sweats in $24 \%$ of the women. These symptoms interfered with the women's daily work performances in $46 \%$ of the cases, affected family life in $28 \%$ and affected social life in $32 \%$ of the cases.

Conclusion: Majority of the women have menopausal symptoms during perimenopause and postmenopausal period. These symptoms have major impact on women's personal, social, and family lives.
\end{abstract}

Key words: Impact, Menopause, Perimenopause, Symptoms

\section{INTRODUCTION}

M enopause is defined as the permanent cessation of menstruation resulting from the loss of ovarian follicular activity ${ }^{1}$. The term perimenopause denotes the period immediate prior to the menopause and the first year after menopause. The average age for menopause ranges between 45-55 years and is different for different population?.

With the increasing life expectancy, women are living longer than their mothers and grandmothers and are spending more than one third of their life in menopause. It is estimated there will be 1200 million women above age 50 years in the world by $2030^{2}$. With increasing population of menopausal women, menopausal health

Address for correspondence

Dr. Nira Singh Shrestha

Associate Professor,

Department of Obstetrics and Gynecology, Kathmandu Medical College Teaching Hospital, Kathmandu, Nepal

E-mail: shresthanira11@gmail.com and related issues will become a major responsibility of any nation. Developing countries have been facing challenges of addressing health related issues of mother and child and most of their resources are utilized on maternal and neonatal health. With growing population of aged people, the need to address the issues related to menopausal health is being felt in the country. As a result, recently Menopausal society of Nepal was formed by a group of gynecologists in the country to improve the menopausal health of the women in the country.

Menopausal symptoms in perimenopausal women can be very mild to very severe with major impact on their lifestyle ${ }^{3}$. The symptoms of menopause are thought to be the result of declining ovarian reserve with resultant declining ovarian hormones. The decline in these hormones is gradual and starts few to several years before the actual menopause. Several factors are thought to influence the age of menopause ${ }^{4}$.

One of the classic menopausal symptoms is change 
in menstrual cycle pattern which is one of the earliest symptoms of menopausal transition. Other symptoms include vasomotor symptoms like hot flashes and urogenital symptoms. Other menopausal symptoms are sleep disturbances, night sweats; cognitive concerns like problems with memory and concentration, psychological symptoms ranging from milder form of moodiness to anxiety to severe form of depression'. In recent years, various researches have been done on symptomatology of menopause and its impact on the life of women as they progress from perimenopause to menopause. However, data from Nepal is limited. This study was done to find out the prevalence of menopausal symptoms and its impact on lives of perimenopausal and postmenopausal women attending gynecology outpatient department (OPD) of Kathmandu medical college teaching hospital (KMCTH).

\section{METHODS}

This is a hospital based, cross sectional, descriptive study done at the gynecological outpatient department of the KMCTH in the month of August 2016. One hundred perimenopausal and postmenopausal women in the age group between 40 to 60 years of age who were attending gynecological OPD for various gynecological problems were enrolled in the study after taking informed consent. The women were assured about the confidentiality and were interviewed in a quiet room one at a time. Menopause was defined as spontaneous cessation of menstruation for at least one year. A pretested structured questionnaire was used to collect the data from the women selected by convenience sampling. Women with long term history of psychiatric illness such as depression, anxiety, schizophrenia were excluded from the study. The questionnaire elicited information on: demographic data of the enrolled subject, menstrual history. The questionnaire consists of a series of questions concerning women's age at menopause and signs and symptoms related to menopause categorized under vasomotor symptoms, psychological symptoms, urogenital symptoms and miscellaneous symptoms like muscle/joint pain. The questionnaire also inquired about the impact these symptoms had on their lives. The severity of the impact that was experienced by the women were based on their perception. Collected data was analyzed by SPSS version 20 and presented in percentage and frequency table.

\section{RESULTS}

The mean age of the women in the study population was 49.98 years $(S D \pm 6.18)$ and mean age at menopause was 48.02 years ( $S D \pm 2.12$ ) with range between 40 to 54 years. Ninety four percent of women complained of one or more symptoms of menopause. Forty two percent of the study population complained of hot flashes. (Table 1)

Most common symptom among the women was mood swings (80\%) and irritability (68\%). Prevalence of other psychological symptoms like anxiety, depression and panic attack were low in this study population. (Table1)

Nearly one third of the study population had urogenital symptoms, sexual problem of decreased libido being the commonest. (Table 1)

Prevalence of musculoskeletal symptoms was present in $18 \%$, whereas complaints of weight gain were present in $28 \%$ of the study population. (Table 1 )

\section{Table 1: Common symptoms of menopause and} their frequency

\begin{tabular}{lc}
\hline Urogenital Symptoms & Percentage \\
\hline Sexual problem/decreased libido & $32 \%$ \\
\hline Urinary Symptoms & $22 \%$ \\
\hline Vaginal dryness & $18 \%$ \\
\hline Vasomotor symptoms & \\
\hline Hot Flashes & $42 \%$ \\
\hline Night sweats & $24 \%$ \\
\hline Psychological Symptoms & \\
\hline Mood swings & $80 \%$ \\
\hline Irritability & $68 \%$ \\
\hline Anxiety & $20 \%$ \\
\hline Low mood or depression & $16 \%$ \\
\hline Panic attacks & $10 \%$ \\
\hline Easy tearfulness & $6 \%$ \\
\hline Other Symptoms & \\
\hline Weight gain & $28 \%$ \\
\hline Muscle/Joint pain & $18 \%$ \\
\hline Difficulty sleeping & $16 \%$ \\
\hline
\end{tabular}

Nearly half of the women said that the menopausal symptoms had impact on their life which negatively affected their work efficiency in $46 \%$, relationship with their family members in $18 \%$, social life activity in $32 \%$, and $16 \%$ of the women felt they could not carryout their home responsibility efficiently. About $2 \%$ of the women had severe negative impact on performing their home responsibility. (Table 2 ) 
Table 2: Impact of menopausal symptoms on women's life

\begin{tabular}{lcccc}
\hline Negative impact on & Mild & Moderate & Severe & Total \\
Work efficiency & $38 \%$ & $8 \%$ & - & $46 \%$ \\
Relationship with family & $18 \%$ & - & - & $18 \%$ \\
\hline Social life activities & $24 \%$ & $8 \%$ & - & $32 \%$ \\
Home responsibility & $12 \%$ & $2 \%$ & $2 \%$ & $16 \%$ \\
\hline
\end{tabular}

Fifty four percent of the women did not have any negative impact on their work efficiency, $82 \%$ of the women enjoyed their relationship with their family, $68 \%$ of the women continued to have good social life, and $84 \%$ of the women could continue with their home responsibility without any difficulty.

None of the women were using hormone replacement therapy at the time of data collection and only $8 \%$ of the women had used it in the past with some improvement in their symptoms.

\section{DISCUSSION}

Studies done so far have shown that the age at onset of menopause varies with populations. The mean age of menopause was found to be influenced by genetics, life style, socioeconomic status, level of education, and nutritional status of the population studied ${ }^{4-6}$. The menopause and perimenopausal age in developing countries have been reported to be earlier as compared to the developed countries ${ }^{4}$. The average age of menopause in western women is 52-53 years whereas it is $47-49$ years in Asian women ${ }^{7-13}$.

In the current study, the mean age of menopause is 48 years which is comparable to the findings of other Nepalese studies. In a study from four districts of Nepal, mean age of menopause was found to be 47 years $^{8}$. Similarly in another study done in Rupandehi District, the mean age of menopause was 46.81 years ${ }^{9}$. The mean age of menopause was 49.9 years in a study by Marahattaet $\mathrm{al}^{10}$, and Chuni et al in Kaski District ${ }^{11}$.

The mean age of menopause of current study is also comparable with studies from other countries such as India and Pakistan that shows range between 46-49 years ${ }^{12,13}$. The age of menopause is similar in studies done at United Arab Emirates and Turkey ${ }^{14,15}$.

Menopausal transition usually starts in early forties when women are in their peak of functionality. Most of the menopausal transition is associated with one or more symptoms and at times severe enough to have major impact on their lives ${ }^{16}$. The prevalence of menopausal symptoms has also been seen to differ in different population. The symptoms are found to be more severe in western population in comparison to the women in eastern part of world ${ }^{17}$.

The prevalence of hot flashes in this study is $42 \%$ which is comparable to the findings of Marahatta et al where the prevalence of hot flashes was $42.3 \%$ and it was $38 \%$ in study by Ghimire et al ${ }^{10,18}$. Madhukumar et al in their study from India noted the prevalence of hot flashes to be $55.9 \%$ and Nusrat et al in their study from Pakistan noted $59.4 \%$ hot flashes ${ }^{19}$, 20 . Prevalence of night sweat was also low in this study in comparison to the findings of Madhukumar et al (36.7\%) and Rahman et al (48.3\%) ${ }^{19,3}$.

The prevalence of psychological symptoms of irritability was $68 \%$ in current study which is also comparable to the studies done by Marahatta et al. But Rahman et al found the prevalence of hot flashes to be $38 \%$ and irritability to be only $36 \%^{10,3}$. This study found low prevalence of Urogenital Symptoms with sexual problem of $32 \%$ and urinary symptoms of $22 \%$ which is very less in comparison to the findings of Marahatta et al with prevalence of urinary problem in $45 \%$, dryness of vagina in $42.3 \%$ and decreased libido in $63.5 \%{ }^{10}$. However, the prevalence of urogenital symptoms is comparable to the findings of Rahman et. al. This noted sexual problem in $31.20 \%$; and bladder problem in $12.80 \%{ }^{3}$. Prevalence of depression ranged from $35-65 \%$ which is higher than findings of this study of $16 \% \%^{16,21-23}$.

Menopausal symptoms in perimenopausal women can be very severe with major impact on their lifestyle ${ }^{3}$, and the impact can be worsened further in the absence of awareness about the menopausal symptoms among the menopausal women and their families. The studies from our neighboring countries have shown the lack of awareness of these problems and the knowledge about the possible intervention to cope with it. The studies showed that the women do not seek help for their problem in most instances ${ }^{24}$. Studies have shown 20-30\% of menopausal women struggle to cope up with everyday life due to their symptoms, $20 \%$ are forced to take time off from their work due to menopausal 
symptoms $^{16,21-23}$. In this study $46 \%$ of the women had impact of menopausal symptoms on their life as they felt it affected their work efficiency negatively in $46 \%$ of the cases, relationship with their family members in $18 \%$, social life $32 \%$, and household work in $16 \%$ of the cases.

This study highlights the impact of menopausal symptoms on women's life, however this study has some limitation due to its small sample size and sampling technique. Due to the cross sectional nature of study there are possibility that the women may have had recall biases while remembering the dates of their menopause. Possibility of biases in the reporting of

\section{REFERENCES}

1. Howkins J, Bourne G. Perimenopause, menopause, premature menopause and postmenopausal bleeding. In: Paduvidri VG, Daftary SN, editors. Shaw's Textbook of Gynaecology. 14th ed. India: Elsevier; 2008. p.37.

2. Hill K. The demography of Menopause.Maturitas. 1996;2(2):113-127.

3. Rahman S, Salehin F, lqbal A. Menopausal symptoms assessment among middle age women in Kushtia, Bangladesh. BMC Res Notes. 2011;4:188.

4. McKinlay SM, Brambilla DJ, Posner JG. The normal menopause transition. Maturitas. 1992;14(2):10315.

5. Luoto R, Laprio J, Uutela A. Age at natural menopause and sociodemographic status in Finland. Am J Epidemiol. 1994;139(1):64-76.

6. Stanford JL, Hartge P, Brinton LA, Hoover RN, Brookmeyer R. Factors influencing the age at natural menopause. J Chron Dis. 1987;40(11):995-1002.

7. Magursky V, Mesko M, Sokolik L. Age at the menopause and onset of the climacteric in women of Martin district, Czechoslovakia. Int J Fertil. 1975;20(1):17-23.

8. Rajbhandari S, Amatya A, Giri K. Relation of Ethnicity and Menopausal Symptoms in Nepal. J South Asian Feder Menopause Soc. 2013;1(2):50-55.

9. Acharya D, Gautam S, Neupane N, Kaphle HP, Singh JK. Health Problems of Women above Forty Years of Age in Rupandehi District of Nepal. Int J Health Sci Res. 2013;3(3):29-36.

10. Marahatta RK. Study of menopausal symptoms among peri and postmenopausal women attending NMCTH. Nepal Med Coll J. 2012;14(3):251-5.

11. Chuni N, Sreeramareddy CT. Frequency of symptoms, determinants of severe symptoms, severity of the menopausal symptoms and its impact on their lives cannot be denied as it was subjective.

\section{CONCLUSION}

Majority of the women have one or more menopausal symptoms of varying severity during perimenopause and postmenopausal period. These symptoms have some impact on women's personal, social, and family life. Menopausal health should get due attention at the government level and strategies to improve the awareness of menopausal health among women, their families, society, and health care providers should be developed. validity of and cut-off score for Menopause Rating Scale (MRS) as a screening tool: a cross-sectional survey among midlife Nepalese women. BMC Womens Health. 2011;11:30.

12. Nisar N, Sohoo NA, Sikandar R. Age and symptoms at natural menopause: a cross-sectional survey of rural women in Sindh Pakistan.J Ayub Med Coll Abbottabad. 2012;24(2):90-4.

13. Khan HG, Hallad SJ. Age at menopause and menopausal transition: Perspectives of Indian rural women. [Cited 2016 October 27]. Available from:http://www.epc2006.princeton.edu/ download.

14. Rizk DE, Bener A, Ezimokhai M, Hassan MY, Micallef R. The age and symptomatology of natural menopause among United Arab Emirates women. Maturitas. 1998;29(3):197-202.

15. Ayranci U, Orsal O, Orsal O, Arslan G, Emeksiz DF. Menopause status and attitudes in a Turkish midlife female population: An epidemiological study. BMC Womens Health. 2010;10:1.

16. Williams RE, Levine KB, Kalilani L, Lewis J, Clark RV. Menopause-specific questionnaire assessment in US population-based study shows negative impact on health-related quality of life. Maturitas. 2009;62(2):153-159.

17. Payer L. International health report: menopause in various cultures. A portrait of the menopause. Carnforth: Parthenon; 1991.

18. Ghimire N, Dhakal P, Norrish D, Dangal G, Sharma $D$, Dhimal M, et al. Menopausal Health Status of Women of Kapilvastu District of Nepal. J Nepal Health Res Counc. 2015;13(31):182-7.

19. Madhukumar S, Gaikwad V, Sudeepa D. A community based study on perceptions about 
menopausal symptoms and quality of life of postmenopausal women in Bangalore rural. Int J Health Sci Res. 2012;2(3):49-56.

20. Nusrat N, Nishat Z, Gulfareen H, Aftab M, Asia N. Knowledge, attitude and experience of menopause. J Ayub Med Coll Abbottabad. 2008;20(1):56-9.

21. Williams RE,Kalilani L,DiBenedetti DB, Zhou $X$, Fehnel SE, Clark RV. Healthcare seeking and treatment for menopausal symptoms in the United States. Maturitas. 2007;58(4):348-358.

22. Karaçam Z,Seker SE. Factors associated with menopausal symptoms and their relationship with the quality of life among Turkish women. Maturitas. 2007;58(1):75-82.

23. Avis NE,Ory M, Matthews KA, et al. Health-related quality of life in a multiethnic sample of middleaged women: Study of Women's Health Across the Nation (SWAN) Med Care. 2003;41(11):1262-1276.

24. Huang $\mathrm{KE}, \mathrm{Xu} \mathrm{L}, \mathrm{I} N \mathrm{~N}$, Jaisamrarn U. The Asian Menopause Survey: Knowledge, perceptions, hormone treatment and sexual function. Maturitas. 2010;65(3):276-83. 